\title{
Validation of scores of use of inhalation devices: valoration of errors*
}

\author{
Validação de escores de uso de dispositivos para inalação: \\ valoração dos erros cometidos
}

\author{
Letícia Zambelli-Simões ${ }^{1}$, Maria Cleusa Martins ${ }^{2}$, Juliana Carneiro da Cunha Possari ${ }^{3}$, \\ Greice Borges Carvalho ${ }^{4}$, Ana Carla Carvalho Coelho ${ }^{5}$, Sonia Lucena Cipriano ${ }^{6}$, \\ Regina Maria de Carvalho-Pinto ${ }^{7}$, Alberto Cukier ${ }^{7}$, Rafael Stelmach ${ }^{7}$
}

\begin{abstract}
Objective: To validate two scores quantifying the ability of patients to use metered dose inhalers (MDls) or dry powder inhalers (DPls); to identify the most common errors made during their use; and to identify the patients in need of an educational program for the use of these devices. Methods: This study was conducted in three phases: validation of the reliability of the inhaler technique scores; validation of the contents of the two scores using a convenience sample; and testing for criterion validation and discriminant validation of these instruments in patients who met the inclusion criteria. Results: The convenience sample comprised 16 patients. Interobserver disagreement was found in 19\% and 25\% of the DPI and MDI scores, respectively. After expert analysis on the subject, the scores were modified and were applied in 72 patients. The most relevant difficulty encountered during the use of both types of devices was the maintenance of total lung capacity after a deep inhalation. The degree of correlation of the scores by observer was $0.97(p<0.0001)$. There was good interobserver agreement in the classification of patients as able/not able to use a DPI (50\%/50\% and $52 \% / 58 \% ; p<0.01)$ and an MD1 (49\%/51\% and 54\%/46\%; $p<0.05)$. Conclusions: The validated scores allow the identification and correction of inhaler technique errors during consultations and, as a result, improvement in the management of inhalation devices.
\end{abstract}

Keywords: Asthma; Dry powder inhalers; Metered dose inhalers; Validation studies.

\section{Introduction}

Asthma is a chronic inflammatory disease that causes airflow limitation and affects the performance of activities of daily living. ${ }^{(1)}$ Pharmacological treatment is essential ${ }^{(2)}$ and is aimed at achieving and maintaining clinical asthma control. ${ }^{(1)}$ Inhalation is the most widely used approach for the treatment of asthma because it allows drugs to reach the lungs in a selective manner, increasing drug concentration in the airways and reducing systemic adverse effects. ${ }^{(1,3,4)}$
Only half of all asthma patients actually use the prescribed medication and do so correctly. ${ }^{(5)}$ Low treatment adherence is related to the fact that patients do not know how to use or have difficulty in using inhaler devices correctly. ${ }^{(3)}$ Asthma education can remedy that, being a key component of asthma management. ${ }^{(6)}$

Incorrect inhaler use can lead to treatment failure by reducing drug concentration in the airways ${ }^{(7,8)}$ and contribute to treatment

*Study carried out at the Hospital das Clínicas, Faculdade de Medicina, Universidade de São Paulo, São Paulo, Brasil.

1. Programa de Pós-Graduação em Ciências, Departamento de Fisiopatologia Experimental, Faculdade de Medicina, Universidade de São Paulo, São Paulo, Brasil.

2. Divisão de Farmácia, Instituto Central, Hospital das Clínicas, Faculdade de Medicina, Universidade de São Paulo, São Paulo, Brasil.

3. Programa de Pós-Graduação em Assuntos Regulatórios. São Paulo, Brasil.

4. Centro de Atenção Psicossocial Pró-Saúde Mental 11 - Álcool e Drogas - Vila Madalena, São Paulo, Brasil.

5. Escola de Enfermagem, Universidade Federal da Bahia, Salvador, Brasil.

6. Serviço de Farmácia, Instituto do Coração, Hospital das Clínicas, Faculdade de Medicina, Universidade de São Paulo, São Paulo, Brasil.

7. Divisão de Pneumologia, Instituto do Coração, Hospital das Clínicas, Faculdade de Medicina, Universidade de São Paulo, São Paulo, Brasil.

Correspondence to: Letícia Zambelli-Simões. Avenida Presidente Wilson, 227, apto. 1B, Itararé, CEP 11320-001, São Vicente, SP, Brasil.

Tel.: 5513 98132-3860. E-mail: zadelle@hotmail.com

Financial support: None.

Submitted: 22 October 2014. Accepted, after review: 26 May 2015. 
nonadherence, making clinical asthma control difficult. ${ }^{(9)}$

The frequency of incorrect use of metered dose inhalers (MDls) ranges from $14 \%$ to $90 \%$, with an estimated mean of $50 \%,{ }^{(10)}$ incorrect MDI use reducing lung drug deposition to less than $20 \%$. In a study of patients using inhaled or oral corticosteroids, increased bronchodilator use, nebulizer use, and hospitalizations were observed in more than $50 \%$ of the patients who did not adhere to treatment. ${ }^{(11)}$

Instruments (or scoring systems) assessing the difficulties that patients face in using inhaled drugs might be useful to reduce those difficulties. By using such instruments, health professionals can devise an educational program targeting the most common errors made by patients, thus improving treatment adherence. There are some scoring systems that assess inhaler technique in patients with lung disease. ${ }^{(12)}$ Although some assess inhaler technique errors, there is no one system that is considered the gold standard for this purpose. Such an instrument could play an important role in the evaluation of patients using inhalers. ${ }^{(13)}$

Leal ${ }^{(13)}$ developed a scoring system to assess the difficulties that patients face in using MDls; the system scores correct and incorrect MDI use, assessing the errors made during MDI use. On the basis of that instrument, Santos et al. ${ }^{(3)}$ developed scoring systems for the assessment of dry powder inhaler (DPI) and MDI technique. Although the aforementioned instruments have yet to be validated for use, they are used in our hospital in order to assess inhaler technique in patients with asthma ${ }^{(3)}$ and in those with COPD.

Instrument validation allows determination of the congruence between the scoring system used and the reality being measured, thus increasing the reliability of the instrument. ${ }^{(14)}$ The use of validated instruments in order to assess inhaler technique in asthma patients will yield results that are more reliable and will ensure data quality.

The objectives of the present study were to validate two scores quantifying the ability of patients to use MDls or DPls; to identify the most common errors made during their use; and to identify the patients in need of an educational program for the use of these devices.

\section{Methods}

This was an open prospective study conducted at a referral university hospital. The study was approved by the local research ethics committee. The inclusion criteria were as follows: having been diagnosed with asthma in accordance with the Global Initiative for Asthma criteria ${ }^{(15)}$; having been in outpatient treatment for at least two years; being in the 15- to 65-year age bracket; having had at least four years of schooling; having no hearing impairment; and agreeing to participate in the study by giving written informed consent. Patients who had previously participated in educational programs regarding the use of asthma medications were excluded.

The study was conducted in three phases: validation of the reliability of the inhaler technique scores (phase 1); assessment of the content validity of the two scores (phase 2); and assessment of the criterion validity and discriminant validity of the instruments (phase 3).

In phase 1, two guest pharmacists (who were blinded to the study methodology) simultaneously evaluated inhaler technique. They used the inhaler technique scores developed by Santos et al. ${ }^{(3)}$ in order to identify the errors made during MDI and DPI use. The instruments provide step-by-step descriptions of MDI and DPI techniques. For each step that is performed correctly, patients receive a score of 1 ; for each step that is performed incorrectly, they receive a score of 0 . For each serious inhaler technique error, points are deducted from those already scored. The final score determines whether a patient is able or unable to use an MDI or a DPl. The pharmacists were trained in the correct use of the aforementioned scoring systems, in accordance with the guidelines established in the Third Brazilian Consensus on Asthma Management. ${ }^{(16)}$ The following drugs were used in the evaluation: for MDls, $250 \mu \mathrm{g}$ of beclomethasone dipropionate and $100 \mu \mathrm{g}$ of albuterol; for DPls, $200 \mu \mathrm{g}$ of budesonide and formoterol + budesonide (6/200 or $12 / 400 \mu \mathrm{g}$; inhalation capsules); and $50 \mu \mathrm{g}$ of salmeterol xinafoate (Diskus ${ }^{\circledast}$ ). The pharmacists proposed changes to facilitate and expedite instrument completion.

In phase 2, an expert panel evaluated the instruments from the previous phase in order to assess their contents. The expert panel comprised three pulmonologists, two pediatric pulmonologists, and two allergists, all of whom had extensive experience in the use of inhalers.

The proposed changes were judged in terms of the relevance of the items assessed by the 
preliminary instruments, the need for additions, deletions, or changes to improve the accuracy of the modified inhaler technique scores being evaluated. After the changes had been systematized by consensus, new MDI and DPI technique scores were developed.

In phase 3, a new sample of patients using DPIs, MDls, or both were randomly selected to participate in the study, the eligibility criteria being the same as those used in the previous phases. They were given placebo-containing inhalers and no instructions on how to use them, being asked to use them in the same manner as they did their own inhalers. Each patient was simultaneously evaluated by two other pharmacists, who were blinded to the changes that had been made. They used the instruments derived from phases 1 and 2 and were not allowed to communicate their decisions to one another. After the evaluation, all patients were instructed on how to use inhalers correctly.

The median and interquartile range of the scores obtained in phase 3 allowed us to establish cut-off values and divide the patients into two groups: the group of patients who were able to use inhalers and that of those who were not. The latter were then enrolled in our pharmaceutical care program.

In phases 1 and 2, we used a convenience sample based on previous validation studies. ${ }^{(14,17-19)}$ The sample size for phase 3 was calculated on the basis of the hypothesis of an association of at least $60 \%$ between the scores given by the pharmacists. Considering a power of 0.95 and a type 1 error of 0.05 , we calculated that a sample size of 31 assessments was required for each inhaler type. The results obtained in phases 1 and 2 were described qualitatively. In phase 3 , the mean scores were compared between the observers, agreements and disagreements being evaluated individually. The major errors made during inhaler use (as assessed by the observers) were described by frequency.

In phase 3, descriptive analysis of the absolute values of MDI and DPI technique scores by observer was performed with the Statistical Package for the Social Sciences, version 18 (SPSS Inc., Chicago, IL, USA). The degree of correlation between the scores by observer was assessed by Cronbach's alpha coefficient. After assessment of data normality, the scores by observer were compared by means of the Mann-Whitney rank sum test, their correlation being determined by Spearman's test, with SigmaStat software, version 3 (Systat Software Inc., San Jose, CA, USA). The chi-square test was used in order to determine interobserver agreement in the classification of patients as being able or unable to use MDls and DPls. Values of $p<0.05$ were considered significant.

\section{Results}

A total of 16 patients participated in phases 1 and 2 of the study. Pharmacists together identified the need for changes in the scoring systems and proposed two preliminary changes: removal of the overall score; and removal of the suggestions section in order to reduce the number of sheets. This resulted in a scoring system consisting of a single table for assessment of inhaler technique, including examples of correct/incorrect inhaler use. Interobserver disagreement in phase 1 was found in 19\% and 25\% of the DPI and MD1 scores, respectively, indicating not only inhaler technique errors made by the patients but also interpretation errors made by the observers (the pharmacists). That level of disagreement was considered acceptable and was of relatively little significance, being clarified and resolved in the subsequent phase.

The expert panel suggested that two changes be made to the DPI technique score, and both suggestions were accepted: the inclusion of an item regarding patient head position (at an angle of more than $90^{\circ}$ or less than $90^{\circ}$ ), patients receiving 1 point for "an angle of less than $90^{\circ}$ " and 0 points for "an angle of more than $90^{\circ}$ "; and the definition of TLC, which was included at the bottom of the page.

With regard to the MDI technique score, the expert panel suggested that eight changes be made, and all of their suggestions were accepted: the item "shaking the inhaler" was changed from "3 times" to "twice or more"; the item "mode of use" was changed to "inhaler use"; the score for the item "in the mouth, with a spacer" was changed to 1 because it provides a correct example of MDI use, as does the item "out of the mouth, without a spacer"; the item "time point" was changed to "time point (rapid inhalation)"; the items "upon actuation" and "immediately after actuation" have the same weight and were therefore merged; the item "only sprays it into the mouth and does not inhale" was changed to "the device is actuated 
directly into the mouth, and the patient does not inhale"; the item "not completely" was changed to "insufficient", whereas the item "adequately" was changed to "sufficient"; and the item "interval" was changed to "time between MD1 actuations". According to all observers and experts, the resulting scoring systems were more practical (Chart 1).

Although the maximum total score remained the same (i.e., nine points) for the instrument assessing MDI technique, it increased (to six points) for the instrument assessing DPI technique. According to the literature, ${ }^{(3,20)}$ a $20 \%$ variation in the total score is acceptable for a patient to be considered able to use an inhaler correctly. For the present study, this means a minimum MD1 technique score of 7.2 and a minimum DPI technique score of 4.8; however, it is not clear whether the aforementioned variation (standard deviation) takes into account whether a given patient received previous training in inhaler use.

A total of 72 patients participated in phase 3 of the present study. The mean age was 41 years, and $82 \%$ were female. Of those patients, 39 were assessed with the MDI technique score and 50 were assessed with the DPI technique score, a total of 89 assessments being performed. Those assessments allowed us to identify the most common difficulties encountered/errors made during inhaler use.

The most relevant difficulty encountered during the use of both types of devices was the maintenance of TLC after a deep inhalation. The number of errors made was higher during MDI use than during DPI use (Table 1). Errors identified in more than 50\% of all tests performed included $<60 \mathrm{~s}$ between MDl actuations, maintenance of TLC for $<10 \mathrm{~s}$ after inhalation, incorrect speed of inhalation, incorrect MDI use without a spacer, and not exhaling prior to inhalation.

Among the patients who used a DPl, the most common errors were maintenance of TLC for $<10 \mathrm{~s}$, not exhaling prior to inhalation, and incorrect speed of inhalation (in 75\%,62\%, and $57 \%$, respectively), as shown in Table 2 .

Of a sample of 72 patients, 60 did not hold their breath correctly, 58 inhaled too quickly, and 6 did not synchronize inhaler actuation with inhalation.

Median MDI technique scores in phase 3 of the study were 4 and 5 for observers 1 and 2, respectively (Table 3). Median DPI technique scores were 4.5 and 5.0 for observers 1 and 2, respectively.

The degree of correlation of the scores by observer was 0.97 , as assessed by Cronbach's alpha coefficient. The correlation was statistically significant ( $p<0.0001)$, as assessed by Spearman's correlation coefficient (Figure 1). There were no significant differences between the scores given by each observer, as assessed by the Mann-Whitney test. The scores were quite similar, indicating criterion validity.

All patients whose MDI and DPI technique scores were $<4$ were enrolled in an educational program. A median score of 4 was the lowest whole number showing interobserver agreement. With regard to discriminant validity, there was good interobserver agreement in the classification of patients as being able/unable to use a DPI $(50 \% / 50 \%$ and $52 \% / 58 \% ; p<0.01)$ and an MDI (49\%/51\% and 54\%/46\%; $p<0.05)$.

\section{Discussion}

The present study allowed assessment of the content validity, criterion validity, and discriminant validity of the DPI and MDI scores. It also allowed identification of the major difficulties that patients encounter when using inhaler devices for the treatment of asthma. Finally, it allowed determination of cut-off scores to classify patients as being able or unable to use their inhalers, the latter patients being enrolled in an educational program.

To the best of our knowledge, there is only one validation study of MDI technique scores (in patients with asthma) ${ }^{(12)}$ and one of DPI technique scores (in patients with COPD). ${ }^{(21)}$ In addition, according to Basheti et al.,(22) although the use of device-specific checklists is the most feasible method for assessing inhaler technique, little evidence is available to assess the relative importance of different criteria. Divergence between the scoring systems for the same inhaler device in different studies makes direct comparison of results difficult. In our study, MDI and DPI technique scores were validated in asthma patients, and the results allowed us to identify MDI and DPI technique errors and address them in a personalized manner, meaning that the instructions provided to patients were based on their own inhaler technique errors.

Our findings corroborate those of other studies. ${ }^{(9,23,24)}$ The inability to hold their breath 
for more than $10 \mathrm{~s}$ after inhalation was the major difficulty that our patients encountered during MDI and DPI use (83\% and 75\%, respectively). Manzella et al. ${ }^{(12)}$ assessed inhaler technique and reported that $69 \%$ of the patients studied did not hold their breath for at least $10 \mathrm{~s}$. A review compiling the results of 12 studies (including 955 patients) identified the most common errors made by patients using inhaler devices, less than $10 \mathrm{~s}$ of breath-holding after inhalation having

Chart 1 - Scoring systems modified and approved by an expert panel (phase 2) and validated for use in Brazil (phase 3).

\begin{tabular}{|c|c|c|c|}
\hline \multicolumn{4}{|c|}{ METERED DOSE INHALER (MDI) TECHNIQUE SCORE } \\
\hline \multicolumn{4}{|c|}{$\begin{array}{l}\text { Name of the patient } \\
\text { Place your hand on the chest of the patient } \\
\text { Ask him or her to inhale and exhale deeply } \\
\text { Use your findings in order to assess depth }\end{array}$} \\
\hline \multicolumn{3}{|c|}{ Criteria } & Score \\
\hline \multirow{4}{*}{$\begin{array}{l}\text { Shaking the inhaler (twice or } \\
\text { more) }\end{array}$} & No & & 0 \\
\hline & Yes & & 1 \\
\hline & Errors & Not shaking the inhaler & -4 \\
\hline & & Removing the canister from the inhaler & -1 \\
\hline \multirow[t]{3}{*}{ Position } & Incorre & & 0 \\
\hline & Correct & & 1 \\
\hline & Error & Removing the spacer & -4 \\
\hline \multirow{3}{*}{$\begin{array}{l}\text { Exhalation (inhale deeply and } \\
\text { then exhale deeply) }\end{array}$} & Yes & & 1 \\
\hline & No & & 0 \\
\hline & Error & Exhaling into the spacer & -2 \\
\hline \multirow[t]{6}{*}{ Inhaler use } & ln the & thout a spacer & 0 \\
\hline & Out of & , without a spacer & 1 \\
\hline & ln the & th a spacer & 1 \\
\hline & Out of & , with a spacer & 0 \\
\hline & Errors & Using the space irregularly & -2 \\
\hline & & $\begin{array}{l}\text { Keeping the mouth open when using the inhaler in } \\
\text { the mouth }\end{array}$ & -2 \\
\hline \multirow[t]{8}{*}{ Time point (rapid inhalation) } & Before & tion & 0 \\
\hline & Upon c & tely after MDI actuation & 1 \\
\hline & Errors & Nasal breathing & -8 \\
\hline & & Inhaling too early (inhaling before MDI actuation) & -4 \\
\hline & & $\begin{array}{l}\text { The device is actuated directly into the mouth, and } \\
\text { the patient does not inhale }\end{array}$ & -4 \\
\hline & & $\begin{array}{l}\text { Inhaling too late (inhaling long after MDI } \\
\text { actuation) }\end{array}$ & -4 \\
\hline & & Inhaling irregularly & -2 \\
\hline & & Breathing shallowly into the spacer & -1 \\
\hline \multirow[t]{2}{*}{ Speed } & High o & & 0 \\
\hline & Low or & & 1 \\
\hline \multirow[t]{2}{*}{ Depth } & Insuffic & & 0 \\
\hline & Sufficie & & 1 \\
\hline \multirow[t]{2}{*}{ Maintenance of TLC } & For $<1$ & & 0 \\
\hline & For 10 & & 1 \\
\hline \multirow[t]{3}{*}{ Time between MDI actuations } & $2 x$ & $<60 s$ & 0 \\
\hline & & $60 \mathrm{~s}$ or more & 1 \\
\hline & Sprayir & nore jets & -4 \\
\hline
\end{tabular}

TLC: total lung capacity. 
Chart 1 - Continued...

\begin{tabular}{|c|c|c|c|}
\hline \multicolumn{4}{|c|}{ DRY POWDER INHALER (DPI) TECHNIQUE SCORE } \\
\hline \multicolumn{4}{|c|}{$\begin{array}{l}\text { Name of the patient } \\
\text { Place your hand on the chest of the patient } \\
\text { Ask him or her to inhale and exhale deeply } \\
\text { Use your findings in order to assess depth }\end{array}$} \\
\hline \multicolumn{3}{|l|}{ (2) } & Score \\
\hline \multirow[t]{2}{*}{ Dose preparation (DPI actuation) } & Incorrect & & 0 \\
\hline & Correct & & 1 \\
\hline \multirow{4}{*}{$\begin{array}{l}\text { Exhalation (inhale deeply and then exhale } \\
\text { deeply) }\end{array}$} & No & & 0 \\
\hline & Yes & & 1 \\
\hline & Errors & Nasal breathing & -4 \\
\hline & & Exhaling into the inhaler & -2 \\
\hline \multirow[t]{4}{*}{ Speed } & High or of $<3 \mathrm{~s}$ & & 1 \\
\hline & Low or $\geq 3 \mathrm{~s}$ & & 0 \\
\hline & Errors & Inhaling irregularly & -2 \\
\hline & & Inhaling shallowly & -1 \\
\hline \multirow[t]{2}{*}{ Depth } & Insufficient & & 0 \\
\hline & Sufficient & & 1 \\
\hline \multirow[t]{2}{*}{ Maintenance of TLC } & For $<10 \mathrm{~s}$ & & 0 \\
\hline & For $10 \mathrm{~s}$ or more & & 1 \\
\hline \multirow[t]{2}{*}{ Position of the head } & At an angle of $m$ & n $90^{\circ}$ & 0 \\
\hline & At an angle of le & $90^{\circ}$ & 1 \\
\hline
\end{tabular}

TLC: total lung capacity.

Table 1 - Proportion of inhaler technique errors as assessed by the metered dose inhaler score.

\begin{tabular}{lc}
\hline \multicolumn{1}{c}{ Evaluation criteria } & Errors, \% \\
\hline Interval of < 60 s between doses (patients are instructed to allow 60 s between doses) & 89 \\
Maintenance of TLC for < $10 \mathrm{~s}$ after inhalation (patients are instructed to hold their breath for 10 s & 83 \\
after inhalation) & 81 \\
Inadequate inspiratory flow rate (patients inhaled too quickly, shallowly, or both) & 73 \\
Incorrect MDl use without a spacer (for patients who used a spacer) & 59 \\
Not exhaling prior to inhalation (patients did not exhale before using their MDls) & 32 \\
Shaking the inhaler only once (patients are instructed to shake their MDls at least twice) & 31 \\
Not shaking the inhaler (patients are instructed to shake their MDls at least twice) & 18 \\
Incomplete inhalation (patients did not perform a deep inhalation maneuver) & 10 \\
Incorrect MDI position (patients are instructed to sit down in such a way that their legs and the floor & 8 \\
form a 90 angle) & \\
Lack of synchronization between MDl actuation and inhalation (the device was actuated before the & 5 \\
beginning of inhalation) & 5 \\
Nasal breathing (patients breathed through their nose during inhalation) & 9.5 \\
The device is actuated directly into the mouth, and patients do not inhale (patients are instructed to \\
place their MDls at a distance of three fingers' breadth from their mouth and inhale after actuation) \\
Others
\end{tabular}

MDI: metered dose inhaler.

been observed in $26 \%$. A period of $10 \mathrm{~s}$ of breath-holding increases drug deposition in the lungs by allowing more time for the particles to settle. ${ }^{(25)}$ The author of the aforementioned review reported that $50 \%$ of the patients were able to hold their breath for $10 \mathrm{~s}$ between doses.
In our study, less than $10 \mathrm{~s}$ of breath-holding after inhalation was the most common error made during MDI use, having been made by $89 \%$ of those who used MDls. A period of $10 \mathrm{~s}$ of breath-holding is important to ensure that a greater quantity of drug reaches the airways. ${ }^{(12)}$ 
Table 2 - Proportion of inhaler technique errors as assessed by the dry powder inhaler score.

\begin{tabular}{lc}
\multicolumn{1}{c}{ Evaluation criteria } & Errors, \% \\
\hline Maintenance of TLC for < 10 s after inhalation (patients are instructed to hold their breath for 10 s & 75 \\
after inhalation) & 62 \\
Not exhaling prior to inhalation (patients did not exhale before using their DPls) & 57 \\
Inadequate inspiratory flow rate (patients inhaled too quickly, shallowly, or both) & 21 \\
Incomplete inhalation (patients did not perform a deep inhalation maneuver) & 18 \\
lncorrect dose preparation (patients did not place the capsule inside their DPls, did not puncture & 5 \\
the capsule before inhalation, or both)* & 3 \\
lnhaling shallowly (patients did not perform a deep inhalation maneuver) & 2 \\
Exhaling into the device (patients exhaled while their DPls were in their mouth) & 2 \\
Nasal breathing (patients breathed through their nose during inhalation) & \\
lnhaling irregularly (patients were unable to inhale continuously) &
\end{tabular}
DPI: dry powder inhaler. *For the DPI type used in the present study (adaptation).

(A)

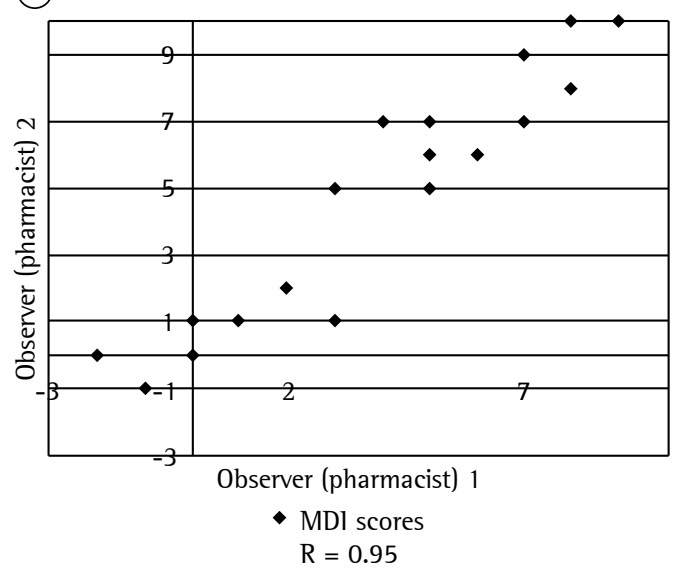

(b)

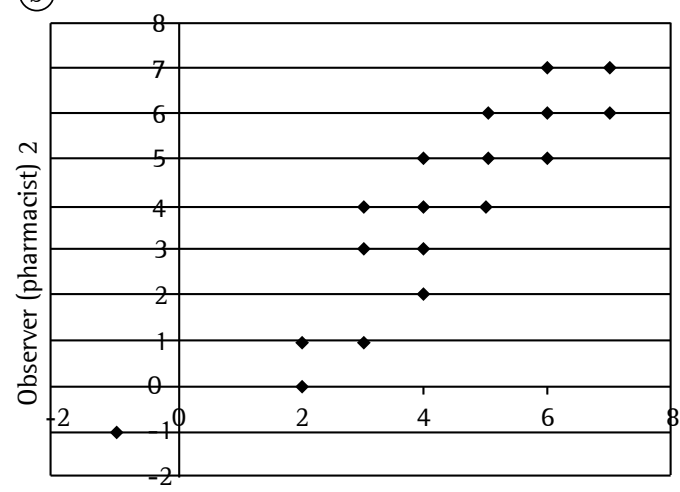

Observer (pharmacist) 1

- DPl scores $\mathrm{R}=0.75$

Figure 1 - Interobserver agreement. In A, metered dose inhaler (MDI) scores. In B, dry powder inhaler (DPI) scores.

Incorrect speed of inhalation was the third most common MDI technique error in our study and was reported by McFadden as the third most common error in 12 studies, inappropriately rapid inspiratory flow rates having been observed in $19 \%$ of the total of patients. This is a serious error, given that a slower inspiratory flow rate translates to higher lung drug deposition with the use of MDls. ${ }^{(25)}$

Not exhaling prior to inhalation was an error made by $62 \%$ of the patients using DPls, being the second most common DPI technique error. The lung volume at the beginning of inhalation interferes with drug deposition, which is why patients should exhale before inhaling. ${ }^{(26)}$

Incorrect speed of inhalation was the third most common DPI technique error (57\%). In order to deliver medication, DPls depend on patient inspiratory flow. If the flow rate (volume/time) is lower than required, the inhaled doses will be lower, and this contributes to treatment failure. ${ }^{(8,27)}$

Sandrini et al. ${ }^{(28)}$ analyzed MDI use in a sample of patients, classifying inhaler technique as correct, slightly incorrect, moderately incorrect, or clearly incorrect. Inhaler technique was classified as incorrect in $48 \%$ of the patients. The most common errors were placing the inhaler in the mouth (68.0\%), inhaling before actuation (15.5\%), inhaling too quickly (11.0\%), and inhaling through the nose (9.0\%). Although our method of evaluation differed from that used in the aforementioned study, our patients made the same errors as did those in that study.

Dalcin et al. ${ }^{(24)}$ and Souza et al. ${ }^{(29)}$ used checklists or forms in order to determine whether patients were using their inhalers correctly at work. Souza et al. ${ }^{(29)}$ found that $54.5 \%$ of the patients who used DPls did not exhale properly before inhaling the medication. This finding is consistent with those of the present study, because that was the second most common error 
Table 3 - Dry powder inhaler and metered dose inhaler technique scores by observer.

\begin{tabular}{lcccc}
\hline \multirow{2}{*}{ Scores } & \multicolumn{2}{c}{ DPl technique } & \multicolumn{2}{c}{ MDl technique } \\
\cline { 2 - 5 } & Observer 1 & Observer 2 & Observer 1 & Observer 2 \\
\hline Median (IR) & $4.5(4.0 / 6.0)$ & $5.0(3.0 / 5.0)$ & $4.0(-0.5 / 6.0)$ & $5.0(1.0 / 6.5)$ \\
Minimum/Maximum & $-1 / 7$ & $-1 / 7$ & $-12 / 9$ & $-13 / 10$ \\
\hline
\end{tabular}

DPI: dry powder inhaler; MDI: metered dose inhaler; and IR: interquartile range.

made by our patients. Dalcin et al. ${ }^{(24)}$ found that the patients who used MDls made more errors than did those who used other types of inhalers, a finding that is also consistent with those of the present study.

In the aforementioned studies, ${ }^{(12,23,25,28,29)}$ the instruments used allowed the authors to quantify and classify the errors made by patients. We found no technical differences between the MDI and DPI techniques used at our institution and those described in the Third Brazilian Consensus on Asthma Management ${ }^{(6)}$ or in the 2012 Brazilian Thoracic Association Guidelines for Asthma Management. ${ }^{(1)}$ However, in addition to providing a step-by-step description of inhaler technique, the scoring systems used in the present study are tools that health professionals can use in order to assess objectively and mathematically the errors that patients make when using inhaler devices. In addition, patients can be classified as able or unable to use their inhalers on the basis of their cut-off scores. This allows health professionals to monitor improvements in inhaler technique in an objective manner.

Our results show that the proportion of MDI technique errors was higher than that of DPI technique errors. This difference might be related to the fact that the correct DPI technique is more easily understandable to patients than is the correct MDI technique. Lavorini et al. ${ }^{(21)}$ conducted a literature review of 47 articles analyzing DPI technique. The results showed that incorrect inhaler use affects drug efficacy, and the authors reported that assessment of inhaler technique is still considered irrelevant by many health professionals. ${ }^{(21)}$

In a study conducted in 2011 in the state of Bahia, Brazil, inhaler technique errors were assessed, and the proportion of errors was found to be low. This was attributed to the fact that the patients in that study were monitored at an asthma referral center; they periodically received instructions and refresher training on inhaler technique from a multidisciplinary team. ${ }^{(5)}$
One of the limitations of the present study is the lack of follow-up. A follow-up evaluation might have allowed us to determine whether there were improvements in inhaler technique. The present study was biased by the fact that the proportion of MDI technique errors was high, with median scores of 4 and 5 for observers 1 and 2, respectively; these scores are significantly different from the score of 7.2 suggested in the literature. ${ }^{(3,20)}$ Given that interobserver agreement was high when a cut-off score of less than 4 was used-a finding that suggests that the MDI score has good accuracy-it can be inferred that many patients were classified as being able to use an MDI despite the fact that they did not obtain the minimum score predicted in theory, i.e., $20 \%$ of a maximum total score of 9 . This underscores the need for reassessing inhaler technique at each visit and for sequential use of the MDI score in a large population sample.

The new MDI and DPl scores will allow the implementation of educational programs proposed in asthma management guidelines and strategies, ${ }^{(15,30,31)}$ which recommend that patients receive ongoing training in inhaler technique to ensure correct inhaler use. By providing pharmaceutical care, pharmacists can instruct patients on how to use their inhaler devices correctly. By using our inhaler technique scores, pharmacists can assess inhaler technique errors and determine whether patients are able to achieve an ideal level of technical correctness (of 80\%) and maintain it throughout the educational program. The present study showed that our inhaler technique scores can reveal exactly what it is that patients are doing incorrectly when using MDls or DPls so that the educational program during follow-up can focus on their errors rather than repeating what they already know.

Inhalation is the most widely used approach for the treatment of asthma, and correct inhaler technique is directly related to the therapeutic efficacy of the drug. Therefore, correct inhaler technique is essential for the efficacy of pharmacological treatment. ${ }^{(3)}$ We believe that 
the present study is clinically relevant because it validated objective MDI and DPI technique scores that can reveal the major difficulties encountered by patients using MDls or DPls and provided cut-off scores that can be used in order to classify patients as being able or unable to use their inhalers. By using the validated scores, health professionals will be able to identify and correct inhaler technique errors during visits and, as a result, improve inhaler use.

\section{Acknowledgments}

We would like to thank Tamara Ferreti, Edilma Reis, and the Clinical Pharmacy Section of the Pharmacy Department of the University of São Paulo School of Medicine Central Institute for their assistance in conducting this study.

\section{References}

1. Sociedade Brasileira de Pneumologia e Tisiologia. Diretrizes da Sociedade Brasileira de Pneumologia e Tisiologia para o Manejo da Asma 2012. J Bras Pneumol. 2012;38(Suppl 1):S1-S46.

2. Sarinho E, Queiroz GR, Dias ML, Queiroz e Silva AJ. Asthma-related hospitalizations and lack of outpatient follow-up treatment. J Bras Pneumol. 2007;33(4):365-71. http://dx.doi.org/10.1590/S1806-37132007000400004

3. Santos Dde 0, Martins MC, Cipriano SL, Pinto RM, Cukier A, Stelmach R. Pharmaceutical care for patients with persistent asthma: assessment of treatment compliance and use of inhaled medications. J Bras Pneumol. 2010;36(1):14-22.

4. Newman SP. Aerosol deposition considerations in inhalation therapy. Chest. 1985;88(2 Suppl):152S-160S. http:// dx.doi.org/10.1378/chest.88.2.152S

5. Coelho AC, Souza-Machado A, Leite M, Almeida P, Castro L, Cruz CS, et al. Use of inhaler devices and asthma control in severe asthma patients at a referral center in the city of Salvador, Brazil. J Bras Pneumol. 2011;37(6):720-8.

6. Prabhakaran L, Lim G, Abisheganaden J, Chee CB, Choo YM. Impact of an asthma education programme on patients' knowledge, inhaler technique and compliance to treatment. Singapore Med J. 2006;47(3):225-31.

7. Inhaler Error Steering Committee, Price D, BosnicAnticevich S, Briggs A, Chrystyn H, Rand C, et al. Inhaler competence in asthma: common errors, barriers to use and recommended solutions. Respir Med. 2012;107(1):37-46.

8. Virchow JC, Crompton GK, Dal Negro R, Pedersen S, Magnan A, Seidenberg J, et al. Importance of inhaler devices in the management of airway disease. Respir Med. 2008;102(1):10-9. http://dx.doi.org/10.1016/j. rmed.2007.07.031

9. Oliveira PD, Menezes AM, Bertoldi AD, Wehrmeister FC, Macedo SE. Assessment of inhaler techniques employed by patients with respiratory diseases in southern Brazil: a population-based study. J Bras Pneumol. 2014;40(5):51320. http://dx.doi.org/10.1590/S1806-37132014000500007

10. Giraud V, Roche N. Misuse of corticosteroid metered-dose inhaler is associated with decreased asthma stability.
Eur Respir J. 2002;19(2):246-51. http://dx.doi.org/10 $.1183 / 09031936.02 .00218402$

11. Heaney LG, Horne R. Non-adherence in difficult asthma: time to take seriously. Thorax. 2012;67(3):268-70. http:// dx.doi.org/10.1136/thoraxjnl-2011-200257

12. Manzella BA, Brooks CM, Richards JM Jr, Windsor RA, Soong S, Bailey WC. Assessing the use of metered dose of inhalers by adults with asthma. J Asthma. 1989;26(4):22330. http://dx.doi.org/10.3109/02770908909073253

13. Leal OM. Análise de fatores potencialmente agravantes da asma brônquica em pacientes tratados com corticoesteróides sistêmicos (thesis). São Paulo: Faculdade de Medicina da Universidade de São Paulo; 1998.

14. Pasquali L. Psychometrics. Rev Esc Enferm USP. 2009;43(spe):992-9. http://dx.doi.org/10.1590/ S0080-62342009000500002

15. Global Initiative for Asthma. Global strategy for asthma management and prevention. Bethesda: National Institutes of Health, National Heart, Lung, and Blood Institute; 2014.

16. Sociedade Brasileira de Pneumologia e Tisiologia. 111 Consenso Brasileiro de Manejo da Asma. J Bras Pneumol. 2002;28(Suppl 1):S1-S57.

17. Camelier A, Rosa FW, Salmi C, Nascimento OA, Cardoso F, Jardim JR. Using the Saint George's Respiratory Questionnaire to evaluate quality of life in patients with chronic obstructive pulmonary disease: validating a new version for use in Brazil. J Bras Pneumol. 2006;32(2):11422. http://dx.doi.org/10.1590/S1806-37132006000200006

18. Borges MC, Ferraz E, Pontes SM, Cetlin Ade C, Caldeira $\mathrm{RD}$, Silva CS, et al. Development and validation of an asthma knowledge questionnaire for use in Brazil. J Bras Pneumol. 2010;36(1):8-13. http://dx.doi.org/10.1590/ S1806-37132010000100004

19. Roxo JP, Ponte EV, Ramos DC, Pimentel L, D’Oliveira Júnior A, Cruz AA. Portuguese-language version of the Asthma Control Test. J Bras Pneumol. 2010;36(2):159-66. http://dx.doi.org/10.1590/S1806-37132010000200002

20. Delgado AB, Lima ML. Contributo para a validação concorrente de uma medida de adesão aos tratamentos. Psicol Saude Doenças. 2001;2(2):81-100.

21. Tommelein E, Mehuys E, Van Hees T, Adriaens E, Van Bortel $\mathrm{L}$, Christiaens T, et al. Effectiveness of pharmaceutical care for patients with chronic obstructive pulmonary disease (PHARMACOP): a randomized controlled trial. Br J Clin Pharmacol. 2014;77(5):756-66. http://dx.doi. org/10.1111/bcp.12242

22. Basheti IA, Bosnic-Anticevich SZ, Armour CL, Reddel HK. Checklists for powder inhaler technique: a review and recommendations. Respir Care. 2014;59(7):1140-54. http://dx.doi.org/10.4187/respcare.02342

23. Laube BL, Janssens HM, de Jongh FH, Devadason SG, Dhand R, Diot P, et al. What the pulmonary specialist should know about the new inhalation therapies. Eur Respir J. 2011;37(6):1308-31. http://dx.doi. org/10.1183/09031936.00166410

24. Dalcin Pde T, Grutcki DM, Laporte PP, Lima PB, Menegotto SM, Pereira RP. Factors related to the incorrect use of inhalers by asthma patients. J Bras Pneumol. 2014;40(1):13-20. http://dx.doi.org/10.1590/ S1806-37132014000100003

25. McFadden ER Jr. Improper patient techniques of metered dose inhalers: clinical consequences and solutions to misuse. J Allergy Clin Immunol. 1995;96(2):278-83. http://dx.doi.org/10.1016/S0091-6749(95)70206-7 
26. Souza LS. Aerossolterapia na asma da criança. J Pediatr (Rio J). 1998;74(3):189-204. http://dx.doi.org/10.2223/ JPED.428

27. Fink JB, Rubin BK. Problems with inhaler use: a call for improved clinician and patient education. Respir Care. 2005;50(10):1360-74; discussion 1374-5.

28. Sandrini A, Jacomossi A, Farensin SM, Fernandes AL, Jardim JR. Aprendizado do uso do inalador dosimetrado após explicação por pneumologista. J Pneumol. 2001;27(1):7-10. http://dx.doi.org/10.1590/S0102-35862001000100003

29. Souza ML, Meneghini AC, Ferraz E, Vianna EO, Borges MC. Knowledge of and technique for using inhalation devices among asthma patients and COPD patients. J Bras Pneumol. 2009;35(9):824-31. http://dx.doi.org/10.1590/ S1806-37132009000900002

30. Lavorini F, Magnan A, Dubus JC, Voshaar T, Corbetta L, Broeders M, et al. Effect of incorrect use of dry powder inhalers on management of patients with asthma and COPD. Respir Med. 2008;(102):593-604. http://dx.doi. org/10.1016/j.rmed.2007.11.003

31. British Thoracic Society [homepage on the Internet]. London: British Thoracic Society [cited 2014 Mar 12]. British Guideline on the management of asthma. 2012. Available from: www.brit-thoracic.org.uk/ 